\title{
Effect of alloy content on microstructure and microchemistry of phases during short term thermal exposure of 9Cr-W-Ta-0.1C reduced activation ferritic/martensitic (RAFM) steels
}

\author{
RAVIKIRANA $^{\mathrm{a}, \dagger}$, R MYTHILI ${ }^{\mathrm{a}}$, S RAJU ${ }^{\mathrm{a}}$, S SAROJA $^{\mathrm{a}, *}$, G PANEERSELVAM $^{\mathrm{b}}$, \\ T JAYAKUMAR ${ }^{\mathrm{a}}$ and E RAJENDRA KUMAR ${ }^{\mathrm{c}}$ \\ ${ }^{a}$ Metallurgy and Materials Group, Indira Gandhi Centre for Atomic Research, Kalpakkam 603 102, India \\ ${ }^{b}$ Chemistry Group, Indira Gandhi Centre for Atomic Research, Kalpakkam 603 102, India \\ ${ }^{\mathrm{C}}$ TBM Division, Institute for Plasma Research, Gandhinagar 382 428, India \\ ${ }^{\dagger}$ Present address: Indira Gandhi Centre for Atomic Research, Homi Bhabha National Institute, \\ Kalpakkam 603 102, India
}

MS received 3 June 2013; revised 3 September 2013

\begin{abstract}
This paper presents the results of an experimental study on the microstructural evolution in 9Cr reduced activation ferritic/martensitic steels during short term thermal exposures. Since the microstructure is strongly influenced by the alloying additions, mainly $W$, Ta and $C$ contents, the effect of varying $W$ and Ta contents on the martensite structure that forms during normalizing treatment and the subsequent changes during tempering of the martensite in the temperature regime of 923-1033 K have been studied. Microstructural changes like subgrain formation and nature of precipitates have been evaluated and correlated to hardness variations. The systematic change in size distribution and microchemistry of $M_{23} C_{6}$ carbide is studied with variation in $\mathrm{W}$ content at different temperatures.
\end{abstract}

Keywords. Reduced activation ferritic/martensitic steels; tempering kinetics; microstructure; microchemistry.

\section{Introduction}

9Cr reduced activation ferritic/martensitic (RAFM) steels have been developed as structural material for test blanket module in the international thermonuclear experimental reactor due to their excellent irradiation resistance and acceptable high temperature mechanical properties (Kai and Klueh 1996; Klueh 2005). The steels developed internationally are primarily of the generic class of $\mathrm{Cr}$ Mo-V-Nb ferritic martensitic steel, where molybdenum has been replaced by tungsten and niobium by tantalum for the purpose of reduced activation. In most of the $9 \mathrm{Cr}-$ W-Ta-based RAFM steels developed internationally, the tungsten content has been varied in the range of 1-2 wt\% and tantalum in the range of 0.02-0.18 wt\% (Alamo et al 1998; Tavassoli et al 2004; Lindau et al 2005; Baluc et al 2007). Such a wide range of composition is expected to lead to a large variation in mechanical properties, because it is well known that tungsten and tantalum play a significant role in controlling the microstructure and in turn mechanical properties of the steel (Mathew et al 2011; Vanaja et al 2012a,b). An extensive research programme was carried out at Indira Gandhi Centre for Atomic Research, Kalpakkam, for generation of tensile, creep,

*Author for correspondence (saroja@igcar.gov.in) fatigue and impact toughness properties database of RAFM steel with four different combinations of $\mathrm{W}$ and $\mathrm{Ta}$ contents, which has enabled the optimization of $\mathrm{W}$ (1.4 wt\%) and Ta (0.06 wt\%) contents, resulting in the development of an India-specific RAFM (INRAFM) steel (Baldev and Jayakumar 2011; Laha et al 2013).

RAFM steel undergoes transformation to austenite at high temperatures, which on cooling decomposes to martensite or ferrite and carbides depending upon the alloy content and cooling rate. Addition of alloying elements like W, Ta and C strongly influences the transformation temperature and characteristics (Raju et al 2009, 2010a,b; Saroja et al 2011). Furthermore, W and Ta content of the steel plays an important role in controlling the kinetics of martensitic transformation and subsequent tempering process (Raju et al 2010a,b). Steel is used in normalized and tempered conditions in all applications. The microstructure that evolves during normalizing and tempering processes as well as during subsequent thermal exposure or service is sensitive to the alloying content in addition to the processing conditions employed. Hence, it is essential to understand the effect of alloy content on the microstructural parameters and microchemistry of different phases that evolve during the normalizing and tempering processes, which influence the microstructures that develop subsequently during long term service and in turn control the properties. 


\section{Experimental}

Four variants of 9Cr RAFM steels have been indigenously developed with $\mathrm{W}$ content in the range of $1-2 \mathrm{wt} \%$ and $\mathrm{Ta}$ in the range of $0 \cdot 06-0 \cdot 14 \mathrm{wt} \%$, in order to arrive at an optimum composition for the India-specific RAFM steel, now termed as INRAFM (Baldev and Jayakumar 2011; Laha et al 2013) through research and development. On the basis of extensive structure-property correlations, the composition of INRAFM has been optimized. Chemical composition of the four RAFM steels employed in this study is shown in table 1 . The steel samples of dimensions, $12 \times 12 \times 12 \mathrm{~mm}$ were normalized at $1253 \mathrm{~K}$ for $30 \mathrm{~min}$ followed by air cooling to room temperature. Subsequently, the steels were subjected to short-term heat treatment in the temperature range of 923-1033 K for durations ranging from $30 \mathrm{~min}$ to $10 \mathrm{~h}$. Preliminary characterization of microstructure was carried out using conventional metallography techniques and scanning electron microscopy (SEM). SEM was carried out using Helios 600i, FEG SEM operated at $20 \mathrm{kV}$. $\mathrm{X}$-ray diffraction (XRD) on sheets of dimensions, $10 \times 10 \mathrm{~mm}$ was carried out using Philips X'pert Pro ${ }^{\circledR}$ with $\mathrm{CuK} \alpha$ radiation and full-width at half-maximum was measured, which was used to evaluate the relative strain using the normalized and tempered steel as the reference. Detailed microstructural analysis of thin foils and carbon extraction replica were carried out using a Philips CM 200 analytical transmission electron microscope (TEM) fitted with X-max silicon drift detector for energy dispersive spectroscopy (EDS) analysis. The hardness measurements were carried out at $10 \mathrm{~kg}$ load using FIE VM-50 PC based Vickers hardness tester.

\section{Results}

\subsection{Effect of $W$ and Ta on microstructural characteristics}

Figure 1(a) shows the scanning electron micrograph of $1.4 \mathrm{~W}-0 \cdot 06 \mathrm{Ta}$ steel in normalized condition, showing a fully martensitic structure. No evidence for $\delta$-ferrite was observed. A similar microstructure was observed for the other two steels with varying tungsten contents. Measurement of prior austenite grain size (PAGS) by the linear intercept method, showed a decrease in the average value from 25 to $12 \mu \mathrm{m}$ and $11 \mu \mathrm{m}$ with increase in $\mathrm{W}$ and Ta, respectively, which is attributed to the pinning effect of the increased number density of undissolved carbides

Table 1. Chemical composition of RAFM steels studied.

\begin{tabular}{|c|c|c|c|c|c|c|c|c|c|c|c|}
\hline \multirow[b]{2}{*}{ Steel } & \multicolumn{11}{|c|}{ Element (wt\%) } \\
\hline & $\mathrm{Cr}$ & $\mathrm{C}$ & $\mathrm{Mn}$ & V & W & $\mathrm{Ta}$ & $\mathrm{N}$ & $\mathrm{O}$ & $\mathrm{P}$ & $S$ & $\mathrm{Fe}$ \\
\hline $1 \mathrm{~W}-0.06 \mathrm{Ta}$ & $9 \cdot 04$ & $0 \cdot 08$ & $0 \cdot 55$ & $0 \cdot 22$ & 1 & 0.06 & $0 \cdot 0226$ & 0.0057 & $0 \cdot 002$ & $0 \cdot 002$ & Bal. \\
\hline $1.4 \mathrm{~W}-0.06 \mathrm{Ta}$ & 9.03 & $0 \cdot 126$ & $0 \cdot 56$ & $0 \cdot 24$ & $1 \cdot 38$ & 0.06 & 0.03 & 0.002 & $<0.002$ & $<0.001$ & Bal. \\
\hline $2 \mathrm{~W}-0 \cdot 06 \mathrm{Ta}$ & 8.99 & $0 \cdot 12$ & $0 \cdot 65$ & $0 \cdot 24$ & $2 \cdot 06$ & 0.06 & 0.02 & $0 \cdot 0024$ & $0 \cdot 002$ & $0 \cdot 0014$ & Bal. \\
\hline $1 \mathrm{~W}-0 \cdot 14 \mathrm{Ta}$ & $9 \cdot 13$ & $0 \cdot 12$ & $0 \cdot 57$ & $0 \cdot 22$ & $0 \cdot 94$ & $0 \cdot 135$ & $0 \cdot 033$ & $0 \cdot 0041$ & $<0.002$ & 0.0015 & Bal. \\
\hline
\end{tabular}
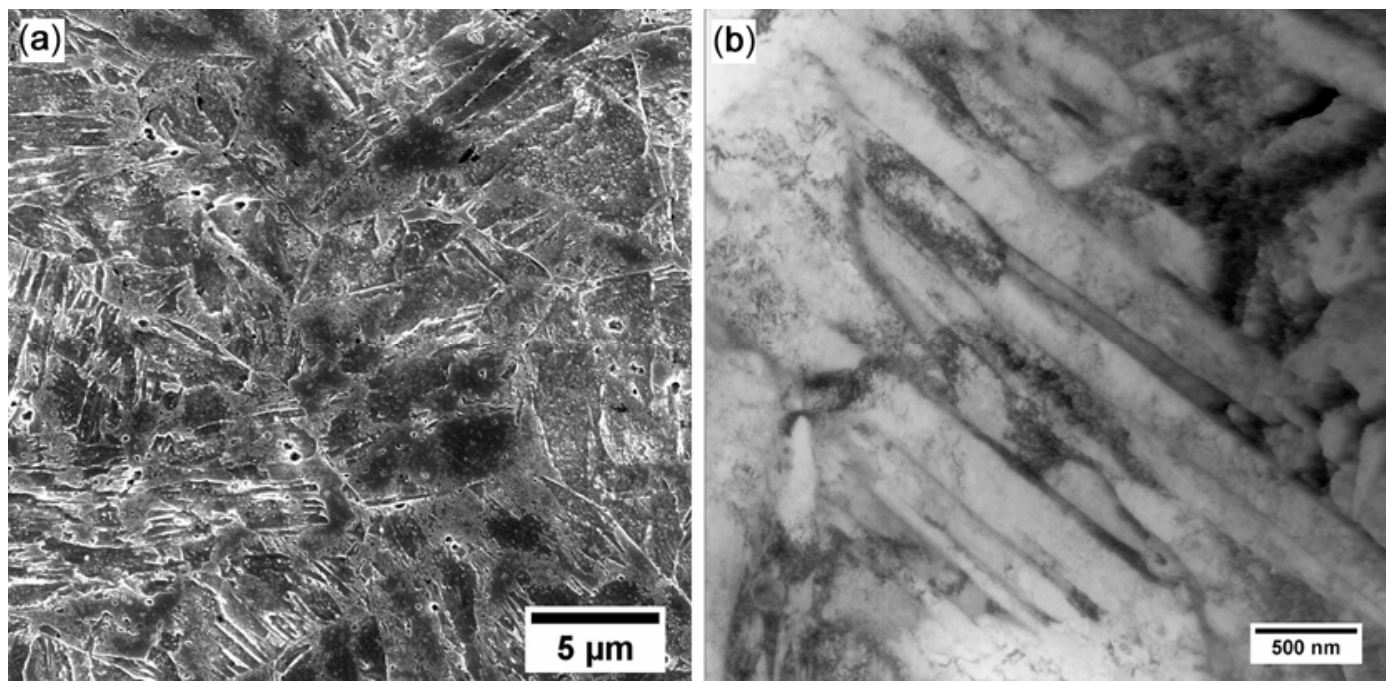

Figure 1. (a) Scanning electron micrograph of 1.4W-0.06Ta steel showing fully martensitic structure after normalizing and (b) transmission electron micrograph showing martensitic laths. 
(Ravikirana et al 2013). A predominantly lath martensite structure was observed from a typical transmssion electron micrograph of the $1 \cdot 4 \mathrm{~W}-0 \cdot 06 \mathrm{Ta}$ steel shown in figure 1(b). The average width of laths measured showed a decrease from 0.36 to $0.24 \mu \mathrm{m}$ with increase in $\mathrm{W}$ from 1 to $2 \mathrm{wt} \%$, while Ta increase did not show significant change. $1 \cdot 4 \mathrm{~W}-0 \cdot 06 \mathrm{Ta}$ steel showed the maximum average hardness $\left(417 \mathrm{HV}_{10}\right)$ among all the four steels.

\subsection{Effect of $W$ and Ta on tempering of martensite}

Figure 2 shows a scanning electron micrograph of $1.4 \mathrm{~W}$ 0.06Ta steel after tempering for $1 \mathrm{~h}$ at $1033 \mathrm{~K}$. A typical tempered martensitic structure is observed, which is also the case for the other steels. The variation of hardness with time for a temperature of $1033 \mathrm{~K}$ is listed in table 2 for the four steels. The variation of hardness as a function of temperature and time for 1.4W-0.06Ta steel is plotted in figure 3(a). The data has been fitted with the following equation

$$
H_{\mathrm{t}}=A \exp (-k t)+H_{\mathrm{sat}},
$$

where $H_{\mathrm{t}}$ is the hardness at any time $t, H_{\mathrm{sat}}$ the saturation hardness and $A, k$ the constants.

Analysis of variation of hardness with time at different temperatures showed the following features:

- A steep decrease in the hardness up to about $2 \mathrm{~h}$, beyond which saturation was reached.

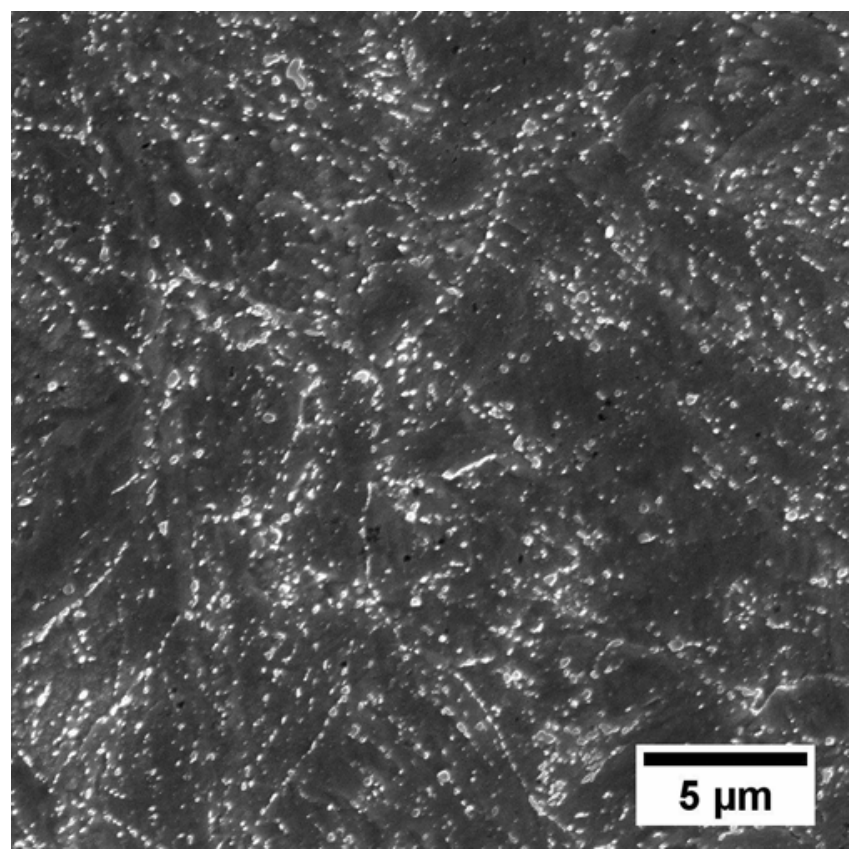

Figure 2. Scanning electron micrograph of normalized and tempered $1.4 \mathrm{~W}-0 \cdot 06 \mathrm{Ta}$ steel showing the presence of precipitates along grain and lath boundaries on tempering for $1 \mathrm{~h}$ at $1033 \mathrm{~K}$.
- The saturation value of hardness was highest for 1.4W-0.06Ta steel despite its high initial hardness in the normalized condition and lowest for $1 \mathrm{~W}-0 \cdot 14 \mathrm{Ta}$ steel.

The kinetics of tempering of martensite has been studied using the rate of change of hardness $(\Delta H / \Delta t)$ (Mythili et al 2000; Vijayalakshmi et al 2000). The plot of $\ln (\Delta H / \Delta t)$

Table 2. The variation of hardness with time for a temperature of $1033 \mathrm{~K}$.

\begin{tabular}{lcccc}
\hline & \multicolumn{4}{c}{ Hardness $\pm 3\left(\mathrm{HV}_{10}\right)$} \\
\cline { 2 - 5 } $\begin{array}{l}\text { Exposure } \\
\text { time (h) }\end{array}$ & $1 \mathrm{~W}-0 \cdot 06 \mathrm{Ta}$ & 1.4W-0.06Ta & 2W-0.06Ta & 1W-0.14Ta \\
\hline 0 & 363 & 417 & 406 & 399 \\
$0 \cdot 5$ & 252 & 267 & 250 & 259 \\
2 & 218 & 227 & 220 & 210 \\
10 & 195 & 211 & 200 & 187 \\
\hline
\end{tabular}
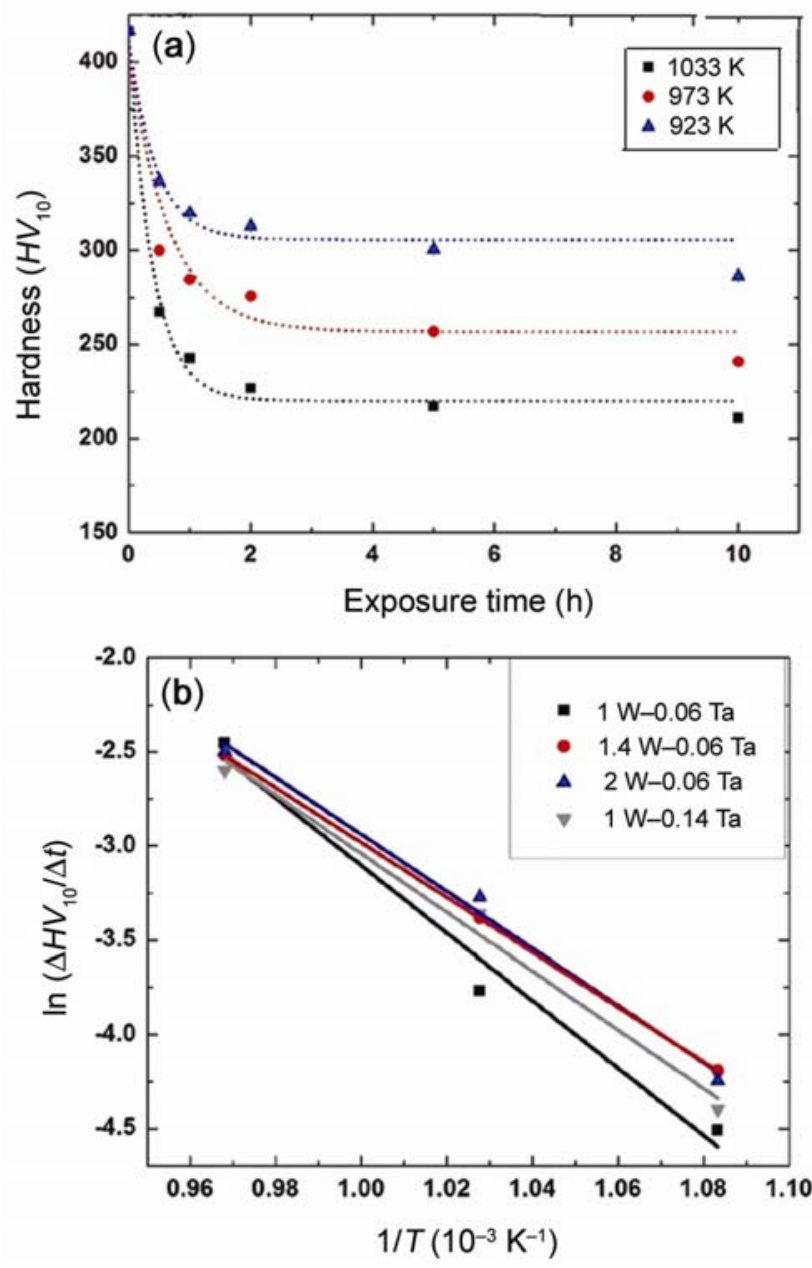

Figure 3. (a) Variation of hardness with time and temperature in 2W-0.06Ta steel showing an exponential decrease and (b) Arrhenius plot for all the four steels. 
Table 3. FWHM for the prominent (2 00 ) and (2 20 ) peaks of $\alpha$-ferrite showing decrease with time/temperature.

\begin{tabular}{|c|c|c|c|c|c|c|}
\hline \multirow{2}{*}{$\begin{array}{l}(h k l) \\
\text { Temperature }(\mathrm{K}) \rightarrow\end{array}$} & \multicolumn{3}{|c|}{ FWHM $_{(200)}$} & \multicolumn{3}{|c|}{$\mathrm{FWHM}_{(220)}$} \\
\hline & 923 & 973 & 1033 & 923 & 973 & 1033 \\
\hline \multicolumn{7}{|l|}{ Time (h) } \\
\hline 0 & $0 \cdot 72$ & $0 \cdot 72$ & $0 \cdot 72$ & $0 \cdot 78$ & $0 \cdot 78$ & $0 \cdot 78$ \\
\hline $0 \cdot 5$ & 0.645 & 0.643 & $0 \cdot 561$ & $0 \cdot 698$ & 0.644 & 0.606 \\
\hline 1 & 0.629 & 0.649 & $0 \cdot 472$ & 0.692 & 0.633 & 0.488 \\
\hline 2 & 0.574 & 0.575 & $0 \cdot 577$ & 0.636 & 0.605 & 0.587 \\
\hline 5 & 0.635 & 0.577 & $0 \cdot 601$ & 0.673 & 0.626 & $0 \cdot 619$ \\
\hline
\end{tabular}
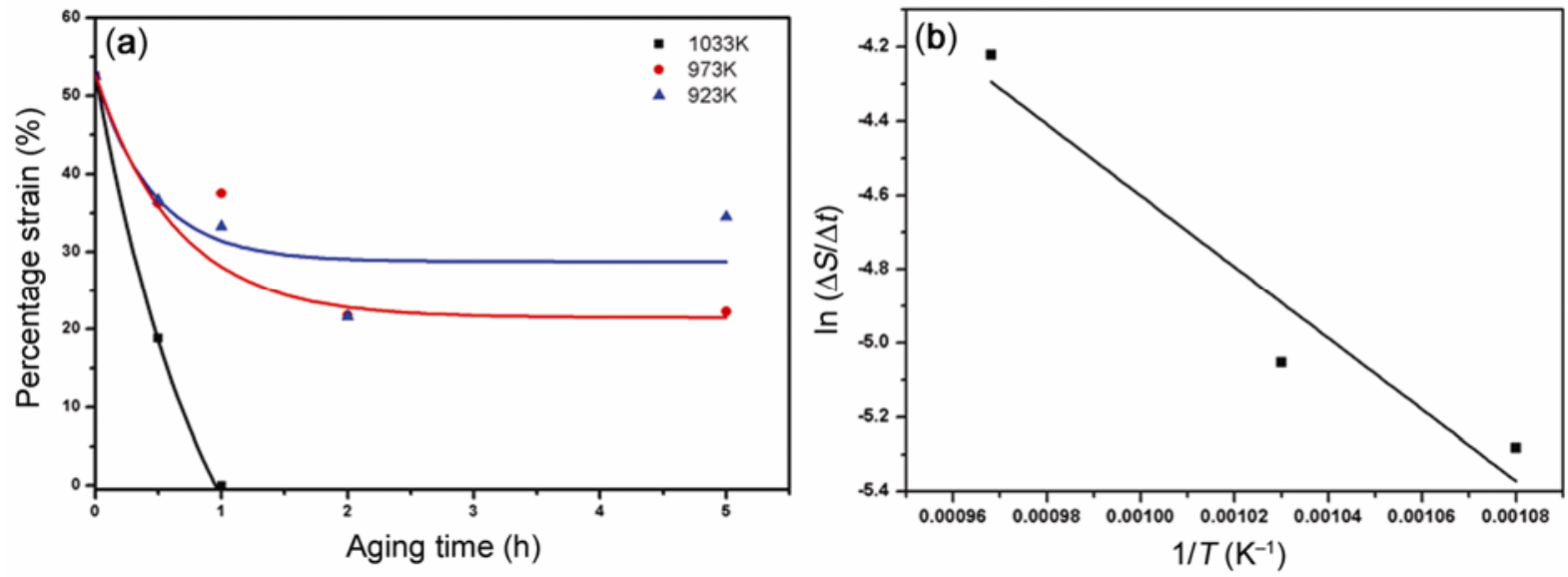

Figure 4. (a) Variation of strain with time and temperature in $1 \cdot 4 \mathrm{~W}-0.06 \mathrm{Ta}$ steel showing an exponential decrease and (b) Arrhenius plot for the determination of activation energy.

$v s$ is $1 / T$ is presented in figure $3(\mathrm{~b})$. It can be seen that it follows the Arrhenius behaviour. Activation energy $(Q)$ for the overall tempering reaction has been calculated from the plot for all the four steels. The calculated values of $Q(\sim 0 \cdot 7-1 \cdot 1 \mathrm{eV})$ correspond to the activation energy for the diffusion of $C$ in $\alpha$-Fe $(0 \cdot 8 \mathrm{eV})$ (Raghavan 1984; Londolt 1990; Anand et al 2009). It is observed that the activation energy decreases with the increase in $\mathrm{W}$ and $\mathrm{Ta}$, suggesting higher rate of recovery at initial stages of tempering in the high $\mathrm{W}$ - and Ta-containing steels.

The mechanism of tempering has also been studied using XRD technique by monitoring the change in strain of the martensite with the increasing temperature and time of tempering. The full-width at half-maxima (FWHM) for the prominent (2 00 ) and (2 20 ) peaks of $\alpha$-ferrite were measured for temperatures of 923,973 and $1033 \mathrm{~K}$ for durations ranging from $30 \mathrm{~min}$ to $5 \mathrm{~h}$ for a typical case of $1.4 \mathrm{~W}-0.06 \mathrm{Ta}$ steel is shown in table 3 . The martensite strain has been calculated using the equation

$$
S=\left(\Delta \mathrm{FWHM} / \mathrm{FWHM}_{\mathrm{ref}}\right) \times 100,
$$

where $\triangle F W H M$ refers to the difference in FWHM value between the heat-treated steel and reference, $\mathrm{FWHM}_{\text {ref }}$ refers to that of normalized (1253 K/30 min) and tempered $(1033 \mathrm{~K} / 1 \mathrm{~h})$ steel. The plot of $S$ vs exposure time (figure 4a) shows an exponential behaviour similar to hardness changes. An Arrhenius plot of $\Delta S / \Delta t$ vs $1 / T$ is presented in figure $4(\mathrm{~b})$. Activation energy $(Q)$ for the overall tempering reaction has been calculated to be $0.5 \mathrm{eV}$.

On the basis of the above studies, it can be concluded that the diffusion of interstitial carbon in ferrite is the rate controlling step for the tempering process and the alloying elements $\mathrm{W}$ and Ta do not play a significant role in the mechanism, but only alter the kinetics of the tempering process.

\subsection{Microstructure and microchemistry during initial stages of tempering}

Transmission electron micrographs of thin foil specimens from 1.4W-0.06Ta steel heat treated for $30 \mathrm{~min}$ at 923 , 973 and $1033 \mathrm{~K}$ are shown in figure 5(a)-(c), respectively. It is observed that recovery of martensite is to a lesser extent at 923 and $973 \mathrm{~K}$, while it is higher at $1033 \mathrm{~K}$. Figure 6(a)-(c) shows thin foil micrographs of 1W-0.06Ta, 2W-0.06Ta and 1W-0.14Ta steels tempered 

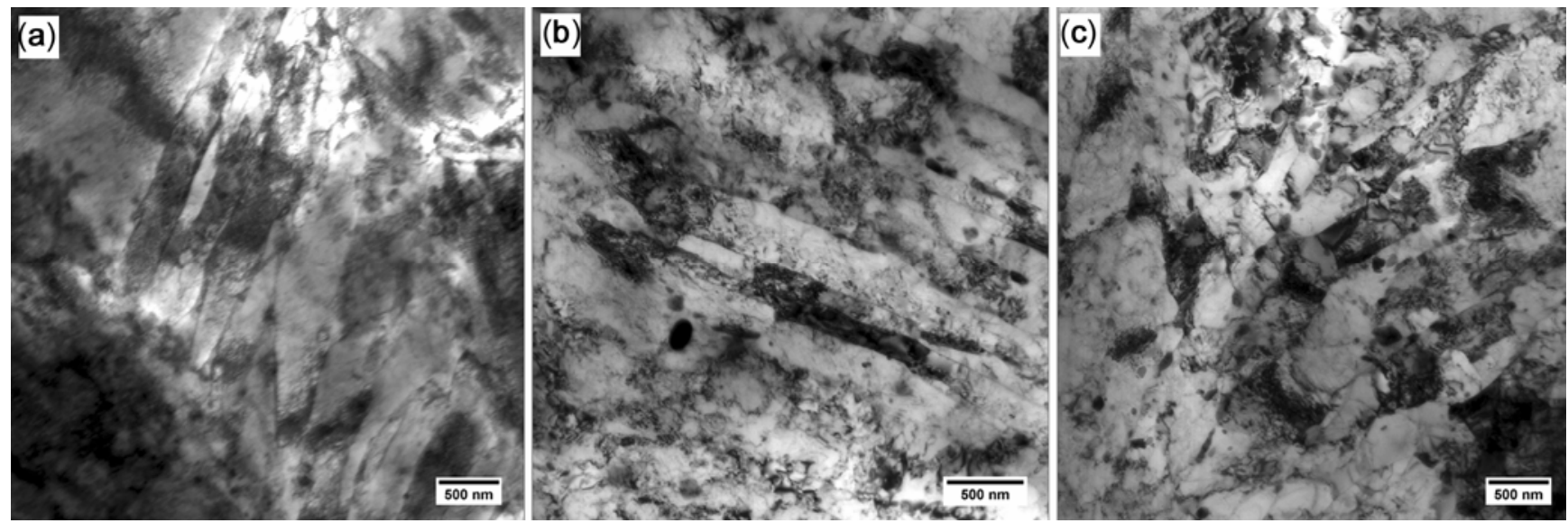

Figure 5. Thin foil micrographs of 1.4W-0.06Ta steel exposed for $30 \mathrm{~min}$ at (a) $923 \mathrm{~K}$, (b) $973 \mathrm{~K}$ showing the retention of lath structure and (c) $1033 \mathrm{~K}$ showing a partial recovery of martensite.
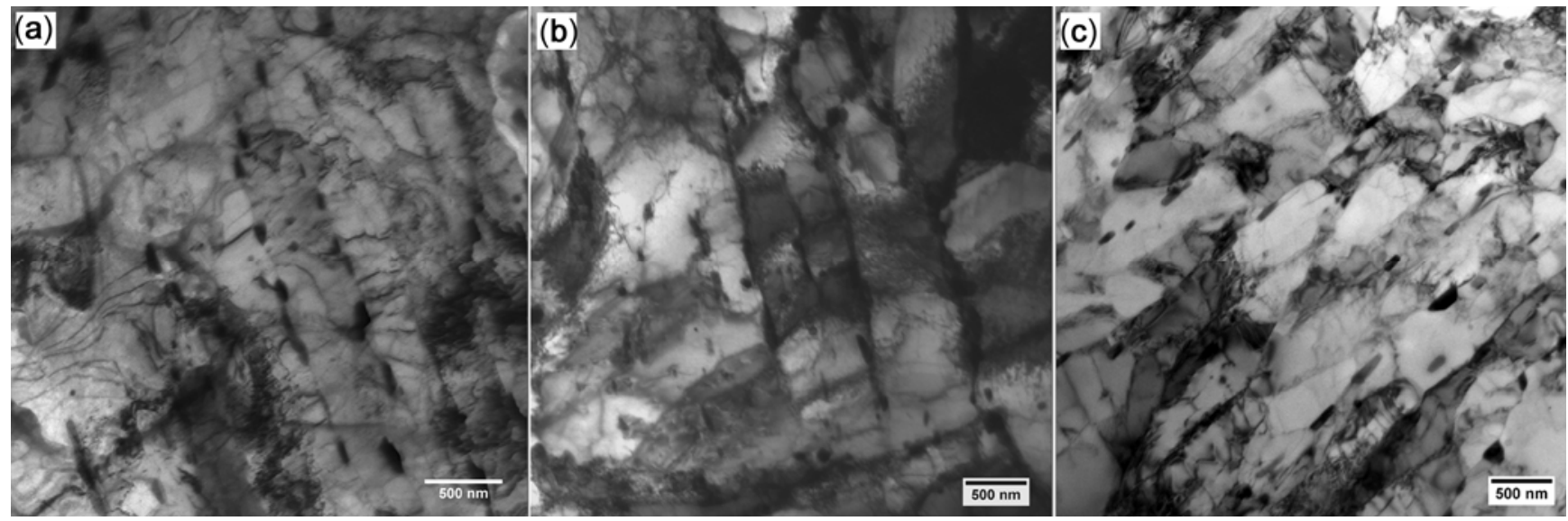

Figure 6. Thin foil micrographs showing partial recovery after tempering at $1033 \mathrm{~K}$ for $1 \mathrm{~h}$ in (a) $1 \mathrm{~W}-0 \cdot 06 \mathrm{Ta}$ steel, (b) $2 \mathrm{~W}-0 \cdot 06 \mathrm{Ta}$ steel and (c) 1W-0·14Ta steel.

at $1033 \mathrm{~K}$ for $1 \mathrm{~h}$. Formation of subgrains is clearly observed, which also suggests the accelerated recovery of martensite with increase in $\mathrm{W}$ and Ta. Detailed analysis of thin foil TEM micrographs showed the following features.

- Slow recovery of martensitic laths at 923 and $973 \mathrm{~K}$.

- Faster recovery of substructure at $1033 \mathrm{~K}$ with the formation of subgrains and coarse secondary phases.

- No significant variation in lath width with time and temperature.

- Higher extent of recovery due to the finer substructure (Ravikirana et al 2013) was evident with the increase in $\mathrm{W}$ and Ta content.

Further studies on carbon extraction replica have been performed to identify and quantify the secondary phases in the steel. Figure 7(a) shows a typical micrograph from 1.4W-0.06Ta steel heat treated for $30 \mathrm{~min}$ at $923 \mathrm{~K}$ along with selected area diffraction (SAD) patterns (figure $7 \mathrm{~b}$ and c) and EDS spectra (figure 7d) from the particles marked in figure 7(a). Comparison of figures 5(a) and 7(a) revealed the presence of fine intralath carbides and coarse interlath carbides with both acicular and globular morphologies. Analysis of SAD patterns and EDS spectra identified the presence of both $\mathrm{M}_{23} \mathrm{C}_{6}$ and $\mathrm{MX}$ precipitates. Fine acicular $\mathrm{M}_{23} \mathrm{C}_{6}$ carbides were Fe-rich, while coarse, acicular and globular $\mathrm{M}_{23} \mathrm{C}_{6}$ carbides were Cr-rich and fine globular MX precipitates were Ta-rich. However, Fe-rich $\mathrm{M}_{23} \mathrm{C}_{6}$ was not observed at higher temperatures and long durations. The presence of Fe-rich $\mathrm{M}_{23} \mathrm{C}_{6}$ was observed in other steels also at low temperatures and shorter durations, though its propensity decreased with the increasing $\mathrm{W}$ content of steel.

Figure 8 shows the size distribution of carbides in 1.4W-0.06Ta steel after $30 \mathrm{~min}$ of heat treatment at 923, 973 and $1033 \mathrm{~K}$. It should be mentioned that while estimating the particle size, $\mathrm{MX}$ and $\mathrm{M}_{23} \mathrm{C}_{6}$ carbides were not distinguished, though the size of $\mathrm{MX}$ precipitates were always less than $50 \mathrm{~nm}$ at all temperatures in all steels. Number density of fine carbides is observed to be high 

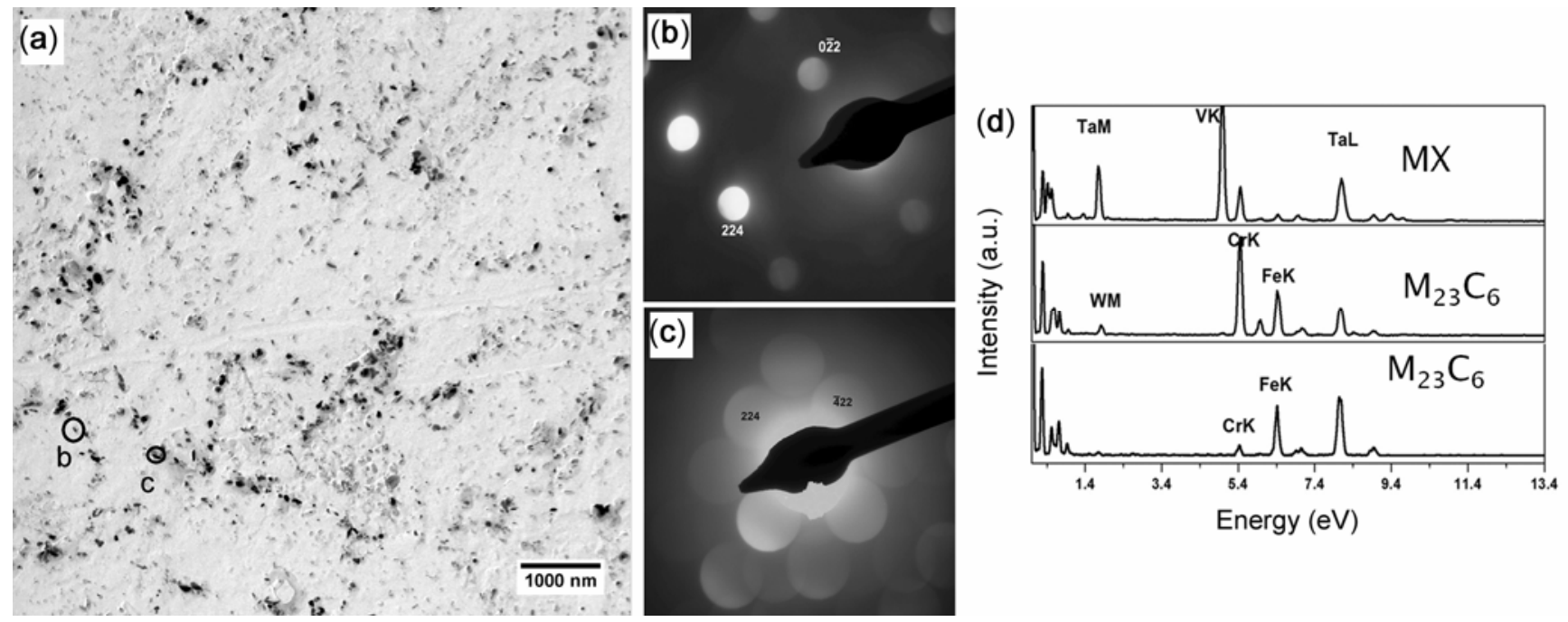

Figure 7. (a) TEM micrographs of extraction replica from 1.4W-0.06Ta steel heat treated at $923 \mathrm{~K}$ for $30 \mathrm{~min}$, (b) SADP from MX with zone axis (-3 11 ), (c) SADP from $\mathrm{M}_{23} \mathrm{C}_{6}$ with zone axis $(-1-53)$, (d) EDS from Fe-rich, Cr-rich and Ta-rich precipitates, respectively.

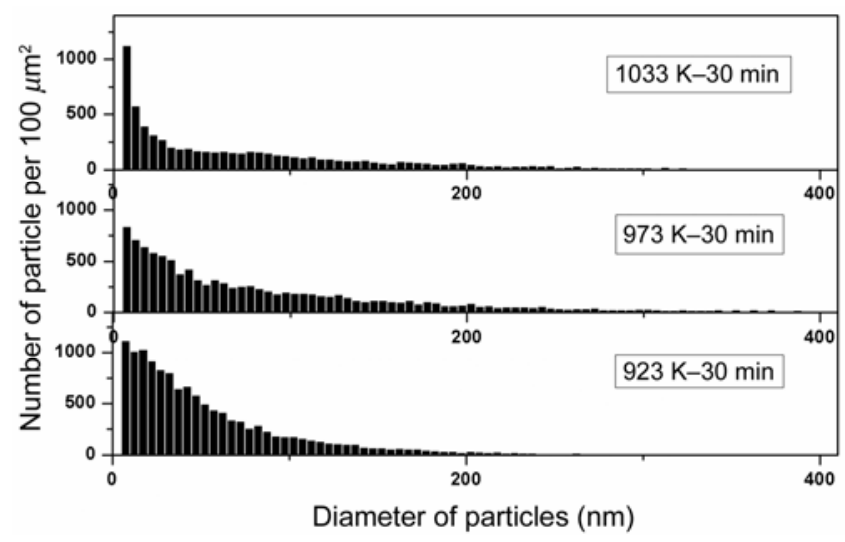

Figure 8. Precipitate distribution in $1 \cdot 4 \mathrm{~W}-0 \cdot 06 \mathrm{Ta}$ steel after exposure for 30 min at 923, 973 and $1033 \mathrm{~K}$ showing decrease in number density and coarsening with temperature.

after 30 min of exposure at $923 \mathrm{~K}$, which decreased with increase in temperature. The coarsening of carbides with temperature is reflected as a peak shift in figure 8. Analysis of size distribution and number density of carbides from carbon extraction micrographs of all the four steels showed decrease in number density and increase in size of carbides with time at any temperature. The increase in temperature accelerated the coarsening as expected. However, it was observed that with the increase in $\mathrm{W}$ content of the steels, the peak corresponding to the maximum frequency shifted towards smaller particle size (250 nm for $1 \mathrm{~W}-0.06 \mathrm{Ta}$ steel to $100 \mathrm{~nm}$ for $2 \mathrm{~W}-0.06 \mathrm{Ta}$ steel after $30 \mathrm{~min}$ at $1033 \mathrm{~K}$ ). This suggests that the coarsening of $\mathrm{M}_{23} \mathrm{C}_{6}$ is controlled by $\mathrm{W}$ addition. The increase in number density of fine precipitates in $1.4 \mathrm{~W}-0.06 \mathrm{Ta}$ and $2 \mathrm{~W}-0.06 \mathrm{Ta}$ steel with high $\mathrm{W}$ is due to

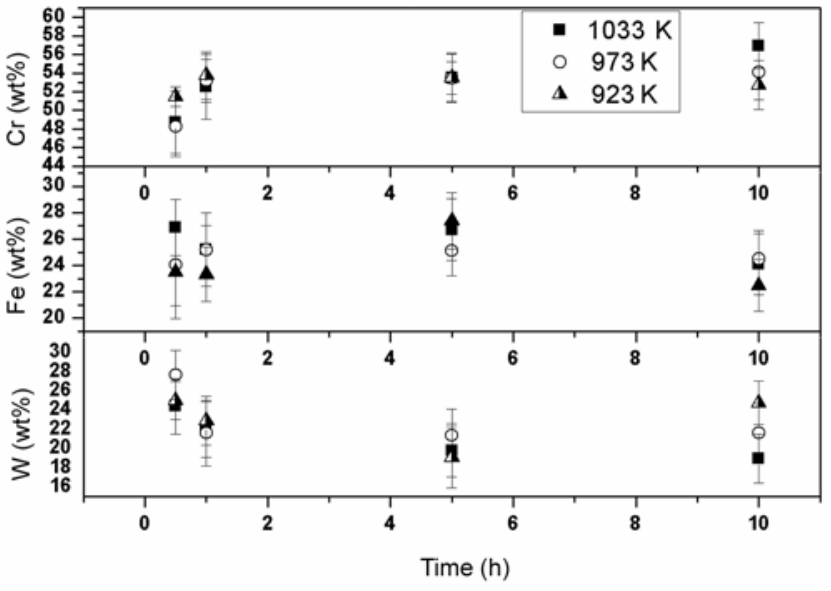

Figure 9. Microchemical variation of $\mathrm{M}_{23} \mathrm{C}_{6}$ carbides in 1.4W-0.06Ta steel with time and temperature; decrease in $\mathrm{Fe}$ and slight increase in $\mathrm{Cr}$ and $\mathrm{W}$ contents are observed with time.

$\mathrm{M}_{23} \mathrm{C}_{6}$, whereas in $1 \mathrm{~W}-0 \cdot 14 \mathrm{Ta}$ with high Ta, the chemistry of the Ta-rich MX is unaltered with the range of Ta content $83-100 \mathrm{wt} \%$; the number density of MX carbides is expected to be high (Ravikirana et al 2013) due to the increased Ta content of the steel.

\subsection{Role of W on microchemistry of $M_{23} C_{6}$}

Figure 9 shows the microchemical variation in $\mathrm{M}_{23} \mathrm{C}_{6}$ with time and temperature in $1.4 \mathrm{~W}-0.06 \mathrm{Ta}$ steel. It is observed that the concentration of $\mathrm{Cr}, \mathrm{Fe}$ and $\mathrm{W}$ was in the range of 50-60, 25-30 and 15-20 wt\%, respectively, at all temperatures and time. However, within this range, a 
decrease in Fe concentration and increase in $\mathrm{Cr}$ and $\mathrm{W}$ concentrations, with tempering time is observed at all temperatures. With increase in the $\mathrm{W}$ content of steels, the $\mathrm{W}$ content of $\mathrm{M}_{23} \mathrm{C}_{6}$ increased while that of $\mathrm{Cr}$ and $\mathrm{Fe}$ decreased at any temperature, which suggests the replacement of Fe by $\mathrm{W}$ in the $\mathrm{M}_{23} \mathrm{C}_{6}$ lattice (Ravikirana et al 2013). Ta-rich MX carbides showed the variation of Ta content in the range 83-100 wt\%, whereas the V-rich MX showed $62-76 \mathrm{wt} \%$ of $\mathrm{V}$ and $24-38 \mathrm{wt} \% \mathrm{Ta}$, which was found to be independent of the Ta content of the steel or the heat treatment given to the steel.

\section{Discussions}

Increase in the $\mathrm{W}$ content from 1 to $1.4 \mathrm{wt} \%$ increased the solid solution strengthening and also the number density of undissolved carbides, which reduced PAGS and lath width due to the pinning effect. As a result, hardness of the steels in normalized condition increased with the $\mathrm{W}$ content up to $1.4 \mathrm{wt} \%$ as discussed in \$3.1. However, further addition of $\mathrm{W}$ did not show significant increase in the hardness (table 2). This can be understood in the light of the presence of large number of coarse undissolved carbides (Mythili et al 2013) in the normalized steel. Increasing the Ta content of the steel from 0.06 to $0.14 \mathrm{wt} \%$ improves the solid solution strengthening, reduces PAGS and modifies the distribution of carbides thereby increasing the hardness, as compared to 1W-0.06Ta steel.

Hardness variation during short time heat treatment is a resultant of the synergistic effect of the following reactions

(1) Decrease in hardness due to annihilation of martensite, induced dislocations at the grain and lath boundaries.

(2) Initial increase in hardness due to nucleation and growth of fine secondary phases $\left(\mathrm{M}_{23} \mathrm{C}_{6}\right.$ and $\left.\mathrm{MX}\right)$, which subsequently decreases the hardness as precipitates coarsen. This also leads to decrease in hardness due to loss of solute elements from ferrite matrix.

In this study, the decrease in hardness (figure 3a) at all temperatures in the initial stages of tempering shows that the effect of dislocation annihilation and decrease in solid solution strengthening dominates over the precipitation strengthening in all the four steels. The saturation in hardness after $2 \mathrm{~h}$ at all temperatures is attributed to a balance between the above reactions. This is also supported by the strain estimated from the FWHM measurements, which show a similar trend. Lower PAG size and lath width provide shorter path for diffusion, which explains the observed steep decrease in hardness with increase in $\mathrm{W}$ and Ta for short durations at all temperatures. The decrease in activation energy $(Q)$ calculated for the steels with increase in the $\mathrm{W}$ and Ta contents also supports the results.

Recovery of martensite laths was slower at 923 and $973 \mathrm{~K}$ due to the sluggish kinetics of self- and substitutional diffusion of Fe and C, respectively. However, increased recovery of martensite was evident at higher temperature of $1033 \mathrm{~K}$ due to the faster diffusion kinetics. The observed faster recovery in the initial stages of heat treatment with $\mathrm{W}$ is attributed to the enhanced diffusion due to the finer substructure. But, the dominant effect of precipitation in the later stages of tempering retards the recovery by pinning the dislocations against the annihilation process, which is expected to enhance the long term thermal stability of the steel. Addition of Ta also enhanced the diffusion due to the finer substructure. But the pinning of dislocation by fine MX carbides slows down the kinetics effectively. Hence, the recovery rate was found to be lower in $1 \mathrm{~W}-0 \cdot 14 \mathrm{Ta}$ steel compared to that of 1W-0.06Ta steel, in spite of having lower PAGS. In addition to the slow kinetics, recovery continued for longer times in $1 \mathrm{~W}-0 \cdot 14 \mathrm{Ta}$ steel leading to the lower saturation hardness at all temperature. This suggests that though fine grains initially increase the kinetics of tempering, increased number density of fine stable intralath MX carbides slow down the kinetics at later stages.

The steady decrease in the Fe content in $\mathrm{M}_{23} \mathrm{C}_{6}$ and the absence of fine intralath Fe-rich carbides as thermal exposure time is increased at low temperatures confirm that they are not stable. These Fe-rich $\mathrm{M}_{23} \mathrm{C}_{6}$ particles gradually dissolve and the stable, coarser Cr-rich $\mathrm{M}_{23} \mathrm{C}_{6}$ carbides evolve at the later stage, which is reflected in their size distribution and number density (figures 8 and 9).

\section{Conclusions}

Systematic studies on the role of $\mathrm{W}$ and Ta on microstructure after short term thermal exposure have been carried out in four 9Cr RAFM steels. The salient features of the studies are as follows:

- Activation energy for the tempering process is found to be in the range of $0 \cdot 5-1 \cdot 1 \mathrm{eV}$, which corresponds to the activation energy for the interstitial diffusion of $\mathrm{C}$ in $\alpha$-Fe.

- Increase in $\mathrm{W}$ and Ta content of steels accelerates the initial tempering due to increased precipitation, which was more significant with increase in $\mathrm{W}$ than Ta.

- Extent of subgrain formation on tempering at $1033 \mathrm{~K}$ was higher with increase in $\mathrm{W}$ and Ta content of the steel.

- Fe-rich $\mathrm{M}_{23} \mathrm{C}_{6}$ carbides were observed at low temperatures and durations, the extent of which increased with $\mathrm{W}$ content of the steel.

- Increase in $\mathrm{W}$ content of steel modifies the chemistry of $\mathrm{M}_{23} \mathrm{C}_{6}$ on thermal exposure and controls its 
coarsening. Increase in Ta did not change the size and composition of MX carbides significantly.

\section{Acknowledgements}

The authors are thankful to Dr P R Vasudeva Rao, Director, Indira Gandhi Centre for Atomic Research, Kalpakkam, India, for his constant support and encouragement for this work. Authors are also grateful to the UGC-DAE Consortium for Scientific Research, for providing experimental facilities for SEM. One of the authors (Ravikirana) acknowledges the Department of Atomic Energy for the fellowship.

\section{References}

Alamo A, Brachet J C, Castaing A, Lepoittevin C and Barcelo F 1998 J. Nucl. Mater. 258-263 1228

Anand R, Sudha C, Karthikeyan T, Terrance A L E, Saroja S and Vijayalakshmi M 2009 J. Mater. Sci. 44257

Baldev Raj and Jayakumar T 2011 J. Nucl. Mater. 41772

Baluc N et al 2007 Nucl. Fusion 47 S696

Kai J J and Klueh R L 1996 J. Nucl. Mater. 230116

Klueh R L 2005 Int. Mater. Rev. 505

Laha K, Saroja S, Moitra A, Sandhya R, Mathew M D, Jayakumar T and Rajendra Kumar E 2013 J. Nucl. Mater. 43941

Lindau R et al 2005 Fusion Eng. Des. 75-79 989

Londolt B 1990 Diffusion in solids, metals and alloys (Berlin: Springer-Verlag) p 372
Mathew M D, Vanaja J, Laha K, Varaprasad Reddy G, Chandravathi K S and Bhanu Sankara Rao K 2011 J. Nucl. Mater. $\mathbf{4 1 7} 77$

Mythili R, Thomas Paul V, Saroja S and Vijayalakshmi M 2000 Proceedings of the international seminar on materials ageing and life management 'ISOMALM 2000' (Kalpakkam) p. 281

Mythili R, Ravikirana, Vanaja J, Laha K, Saroja S, Jayakumar T, Mathew M D and Rajendrakumar E 2013 Proc. Eng. 55295

Raghavan V 1984 Materials science and engineering (New Delhi: Prentice-Hall) p 168

Raju S, Jeya Ganesh B, Arun Kumar Rai, Mythili R, Saroja S, Mohandas E, Vijayalakshmi M, Rao K B S and Baldev Raj 2009 J. Nucl. Mater. 389385

Raju S, Jeya Ganesh B, Arun Kumar Rai, Mythili R, Saroja S and Baldev Raj 2010a J. Nucl. Mater. 40559

Raju S, Jeya Ganesh B, Arun Kumar Rai, Saroja S, Mohandas E, Vijayalakshmi M and Baldev Raj 2010b Int. J. Thermophys. $\mathbf{3 1} 399$

Ravikirana R, Mythili S, Raju S, Saroja T, Jayakumar E and Rajendra Kumar 2013 Mater. Charact. 84196

Saroja S, Dasgupta A, Divakar R, Raju S, Mohandas E, Vijayalakshmi M, Bhanu Sankara Rao K and Baldev Raj 2011 J. Nucl. Mater. 409131

Tavassoli A-A F et al 2004 J. Nucl. Mater. 329-333 257

Vanaja J, Laha K, Mythili R, Chandravathi K S, Saroja S and Mathew M D 2012a Mater. Sci. Eng. A533 17

Vanaja J, Laha K, Shiju Sam, Nandagopal M, Panner Selvi S, Mathew M D, Jayakumar T and Rajendra Kumar E 2012b J. Nucl. Mater. 424116

Vijayalakshmi M, Saroja S, Mythili R, Thomas Paul V and Raghunathan V S 2000 J. Nucl. Mater. 279293 